\title{
Projetos Educacionais para a Popularização das Geociências e para a Geoconservação
}

\author{
Educational Projects for the Public Understanding of Geosciences and Geoconservation
}

\author{
Kátia Leite Mansur (kmansur@drm.ri.gov.br) \\ Serviço Geológico do Estado do Rio de Janeiro - DRM-RJ \\ R. Marechal Deodoro 351, CEP 24030-060, Niterói, RJ, BR \\ Recebido em 18 de maio de 2009; aceito em 17 de julho de 2009
}

\section{RESUMO}

A divulgação das Geociências para a sociedade é pouco disseminada no Brasil. No Estado do Rio de Janeiro um processo sistemático de popularização da Geologia teve início em 2000 com o Projeto Caminhos Geológicos - PCG pela implantação de painéis interpretativos. Eles se tornaram importantes pontos de acesso ao círculo da educação formal e também atraíram o cidadão comum, que passou a se interessar pelos temas geológicos através da presença curiosa de totens em seu caminho. As informações geradas pelo PCG têm alimentado programas de educação e promovido a geoconservação pela discussão dos temas geológicos com organizações ambientalistas, antes focadas apenas no meio biótico. Constata-se que a Geologia, embora embutida nas disciplinas de Ciências e Geografia do ensino fundamental e médio, de maneira geral, não é adequadamente ensinada, seja por deficiência na formação dos professores, seja pela qualidade do material didático disponível. Pode-se dizer que o nível do conhecimento repassado não é suficiente para suprir de informações um aluno com um mínimo de interesse sobre a origem e evolução da Terra. Os Museus de Ciências e ações de universidades vêm complementando esta lacuna, porém, os resultados são ainda modestos, dadas às dimensões do Brasil e às necessidades de investimentos. A apropriação do conhecimento pelas pessoas e organizações populares é a base para o sucesso de projetos de divulgação e gestão do patrimônio geológico, fundamento para a proposição de um Geoparque. Somente o envolvimento das comunidades locais na gestão do espaço delimitado pode promover a sustentabilidade financeira e ambiental requerida. O desafio a ser vencido é o de romper com o isolamento imposto por uma linguagem entendida por poucos.

Palavras-chave: Disseminação da Ciência; Popularização da Ciência; Geoconservação; Projeto Caminhos Geológicos; Geoparque.

\begin{abstract}
The dissemination of geosciences to its citizens is not widespread in Brazil. The Caminhos Geológicos Project, in Rio de Janeiro State began in 2000, with the objective to increase the geological knowledge of the population. The project uses a large number of strategies to reach the population, such as the deployment of interpretative panels, educational projects in geology inside schools, scientific events open to the society, and many others. The panels have become an important source of geological information, especially for students and teachers that live in the region where they have been implanted. The information generated by the project has served as a source for the educational programs, and promotes geoconservation by discussion of the geological issues with environmental organizations, that were previously focused only the biota. Geology is not adequately taught in elementary or in high schools. This is related in part to a deficiency in teacher training, and on the other hand to the quality of didactic material available. The museums of science and universities are attempting to fill this gap. However, the results are less than desirable because of the large dimensions of Brazil and the need for large investments. The diffusion of the knowledge to all the citizens, companies and local authorities is the basis for the success of projects for dissemination and management of geological heritage. This is one of the basic premises to convert an area into a Geopark. Only the involvement of local communities in this subject can promote and support financial resources, sustainability, and environmental demand in the management of a Geopark. The challenge and final aim is to disseminate the information and break the isolation imposed by the hermetic scientific language of geology.
\end{abstract}

Keywords: Dissemination of Science; Public understanding of Science; Geoconservation; Caminhos Geológicos Project; Geopark. 


\section{DIVULGAÇÃO CIENTÍFICA: COMO E PARA QUEM}

O termo vulgarização científica é derivado do francês, enquanto que a denominação popularização tem uso preponderante na língua inglesa. No Brasil o termo vulgarização foi adotado até a primeira metade do século 20, porém, atualmente, foi preterido por difusão, disseminação e divulgação. Independente da opção, todos querem atingir o mesmo objetivo: transmitir uma mensagem com conteúdo científico, por meio da decodificação dos termos pouco usuais para uma linguagem acessível ao público leigo. Busca-se, portanto, alcançar o maior número de pessoas.

Segundo Candotti (2002), educar e prestar contas do que se estuda e investiga é imperativo e fundamental nas sociedades democráticas. Estes conceitos, associados a que a livre circulação das ideias e resultados de pesquisas são fundamentais para o próprio avanço da ciência, são alguns dos pressupostos contidos na "Declaração sobre a ciência e o uso do conhecimento" que a UNESCO preparou para a conferência mundial sobre a ciência, realizada em Budapeste, em junho de 1999. O mesmo autor mostra preocupação quanto à resistência dos próprios pesquisadores em promover a circulação veloz dos conhecimentos, por temerem a imprecisão e a rapidez com que se pode difundir um conceito equivocado.

Alguns autores não veem perspectivas de entendimento dos temas científicos por parte da população, mas todos concordam que é fundamental que não se faça concessão ao rigor dos conceitos. Outros acreditam que o leigo perspicaz e inteligente não é um mito e que existem aos milhões (Gould, 1992). Almeida (1931, in Massarani, 1998) identificou que é importante que as pessoas se mantenham o máximo possível em contato com a ciência. Mesmo que elas não assimilem os conceitos específicos, será fixada uma mentalidade coletiva associada à ciência.

Massarani, Moreira e Brito (2002) são da opinião que:

"Muitas iniciativas ligadas à divulgação da ciência têm despontado no Brasil nas últimas duas décadas. Novos centros e museus de ciência foram criados, livros e revistas foram publicados em número crescente, conferências públicas e eventos divulgativos se espalharam pelas principais cidades do país, temas da biotecnologia moderna galvanizaram interesse em jornais e na TV [...]. Apesar desse esforço, estamos ainda longe de uma divulgação científica de qualidade e que atinja amplos setores da população brasileira; um caminho longo e tortuoso ainda está por ser percorrido. Do ponto de vista da formação de profissionais na área de comunicação em ciência, as iniciativas são inci- pientes e o quadro se mostra ainda bastante frágil do lado das análises e reflexões teóricas sobre as atividades de divulgação. Freqüentemente, a divulgação científica é vista e praticada ou como uma atividade voltada sobretudo para o marketing científico de instituições, grupos e indivíduos ou como uma empreitada missionária de "alfabetização" de um público encarado como um receptáculo desprovido de conteúdo. Entre os desafios permanentes, estão a análise do papel, dos rumos, das estratégias e das práticas da divulgação científica e o entendimento das relações entre ciência e público e da inserção cultural da ciência” (página 9).

Se para a ciência em geral a divulgação para a sociedade enfrenta problemas, maiores ainda são os obstáculos para a disseminação de conceitos geológicos, normalmente restritos aos meios acadêmicos. Uceda (1996) constata que, até na Espanha, onde o inventário de sítios geológicos iniciou-se em 1978, o Patrimônio Geológico tem recebido menor atenção do que outros tipos de patrimônio, elencando duas causas principais:

a. desinteresse dos geólogos, que têm sua atuação mais centrada na prospecção de recursos minerais, energéticos e hídricos ou em obras públicas, o que só recentemente vem mudando pela maior integração com os temas ambientais;

b. a maioria das pessoas tem mais interesse pelos seres vivos do que pelos "elementos inertes" do meio natural e porque o componente geológico requer maior abstração para seu entendimento, em especial quanto ao tempo envolvido (bilhões e milhões de anos). Mondéjar (2007) informa que este quadro permanece ainda hoje e credita o problema a uma falha no sistema educacional espanhol.

Boulton (2001) analisa a questão do interesse da sociedade pela geologia a partir da vivência de problemas relacionados aos riscos decorrentes de fenômenos associados à dinâmica da Terra. Ele afirma que na Grã-Bretanha todos sabem que houve dinossauros, deriva continental e idade do gelo no passado da Terra, mas o fato de não existir atualmente risco de erupções vulcânicas e terremotos afasta o interesse dos eventos geológicos que, a priori, não trazem perigo imediato para a população. Isto também deve servir para o Brasil, onde a ausência de catástrofes de cunho estritamente geológico pode levar ao desinteresse por conhecer mais profundamente a ciência. Vale ressaltar que não são poucos os casos brasileiros de contaminações de águas subterrâneas e de ocorrência de fluxos gravitacionais com consequências desastrosas, causados ou acelerados por ação antrópica que, no entanto, não são entendidos pela população como fenômenos com componente geológico. 


\section{PORQUE DIVULGAR A GEOLOGIA}

Apesar de ser clara a relação entre a biota e o sistema físico da Terra, em geral cada um deles é tratado de forma separada e com pesos distintos quando da gestão dos recursos naturais. Gordon e Leys (2001), baseados nos resultados de mais de 50 anos de trabalhos de inventário, divulgação geológica e geoconservação na Escócia, afirmam que três grandes linhas devem ser unificadas para o sucesso de um programa de conservação do patrimônio natural: a) amplo conhecimento e aceitação da relação entre os sistemas físicos e biológicos da Terra; b) promoção da gestão sustentável do ambiente baseado na aplicação do conhecimento das Ciências da Terra; e c) ampliação do entendimento do público e do seu envolvimento nas questões relacionadas ao patrimônio natural.

Fica claro, portanto, que não se trata de discutir (ou provar) que um tipo de sistema é mais importante do que o outro e sim que ambos estão interligados e devem ser tratados de forma integrada, numa visão holística. O simples fato de que a geodiversidade é o substrato onde a vida se desenvolve e o homem constrói é motivo suficiente para ser tratada com a mesma importância que a biodiversidade.

Com base nestes conceitos é que se torna necessária a construção de uma agenda para proteção do patrimônio natural baseada na divulgação dos seus vários aspectos e não somente na fauna e flora e nas belas geoformas que a natureza produz. Assim, a importância científica e didática do patrimônio geológico deve ser tratada em igualdade de condições com a sua beleza cênica, relacionada, em geral, aos seus atributos turísticos que, apesar de importantes, não são os únicos a conferir valor ao monumento. A função do meio geológico como suporte para os sistemas ecológicos deve ser divulgada e esclarecida para o público em geral.

Brilha (2005) apresenta a execução das seguintes etapas como requisitos básicos para se promover a Geoconservação de uma dada área:

a. Inventário: levantamento da área a ser inventariada em função dos critérios de avaliação/descrição e escala de trabalho (Lima, 2008).

b. Quantificação: busca demonstrar a relevância do patrimônio para dar suporte às ações de geoconservação, com o mínimo de critérios subjetivos. Em geral os métodos de avaliação quantitativa dos geossítios utilizam critérios de valor intrínseco, potencial de uso e necessidade de proteção (Uceda, 1996) para valoração do patrimônio geológico.

c. Classificação (ou Proteção Legal): refere-se ao enquadramento dos geossítios de interesse na legislação de proteção. No Brasil não existe uma figura específica para proteção do patrimônio geológico dentro da Lei do SNUC - Sistema
Nacional de Unidades de Conservação - Lei Federal 9985, de 18 de julho de 2000, que regula as áreas protegidas. Os sítios de valor histórico, paisagístico, artístico, arqueológico, paleontológico, ecológico e científico, estão protegidos pela Constituição Federal (artigo 216) como patrimônio cultural brasileiro. Também, em seu artigo 24, cita a categoria de patrimônio do tipo turístico como um bem e direito a ser protegido.

d. Conservação: pressupõe a manutenção da integridade do geossítio, podendo incluir restrições de uso e até a implantação de barreiras físicas para impedir a aproximação do visitante. Vale ressaltar que a retirada de amostras pode danificar o afloramento, suprimindo algumas feições/estruturas raras ou didáticas que foram descritas, por exemplo, em publicações de referência. Aliás, a The Geologists’ Association, de Londres, publicou um código de conduta <http://www. amlwchhistory.co.uk/parys/geology\%20field\%20work\%20 code.pdf $>$ para trabalhos de campo (Geological Fieldwork Code). Outras formas comuns de degradação de afloramentos são ações de vandalismo (pichação, por exemplo), roubo de amostras (em particular de fósseis) ou o uso indiscriminado de miniperfuratrizes em afloramentos de ampla visitação didática ou científica (Figura 1).

e. Valorização e Divulgação: valorização significa o conjunto de ações executadas para demonstrar a importância do geossítio e, para este conceito, associa o exemplo dos painéis interpretativos, folhetos, mídia eletrônica, entre outros. A compreensão pela população dos fenômenos que geram os monumentos geológicos é essencial para a promoção da Geoconservação, porém, a divulgação da informação à sociedade deve ser feita desde que ela não leve perigo à integridade do local.

f. Monitoramento: acompanhamento sistemático da situação dos geossítios para verificação do possível alcance das ações antrópicas sobre eles. Vale ressaltar que algumas alterações podem ser naturais, como, por exemplo, erosão ou crescimento de vegetação. A capacidade do local em receber visitantes deve ser avaliada.

\section{FERRAMENTAS PARA DIVULGAÇÃO}

\section{Generalidades}

Após um período em que a educação ambiental no Brasil era considerada uma atividade de pouca base científica e muita propaganda (por vezes de grupos ou indivíduos), pode-se dizer que o movimento amadureceu e hoje se encontra aberto para tratar e ouvir sobre temas relacionados a amplas áreas do conhecimento humano. O nome educação ambiental, desgastado pelo uso inadequado, hoje vem sendo resgatado por uma ampla ação que envolve professores, pesquisadores em educação, ambientalistas, cientistas, 
comunidades tradicionais, jovens, adultos e idosos. São os denominados coletivos educadores ambientais, cujas organização e ação vêm sendo estimuladas pelo governo federal, por meio da Política Nacional de Educação Ambiental - PNEA, instituída pela lei $n^{\circ}$ 9.795, de abril de 1999. No rastro desta lei, foi criado o Programa Nacional de Educação Ambiental - ProNEA, a partir do qual se elaborou o Programa Nacional de Formação de Educadores(as) Ambientais. Segundo o MMA (2009), esta "dinâmica articulada, autônoma e interdependente tem como orientação, ou por utopia, a formação de 180 milhões de brasileiros educados e educando ambientalmente e tem na formação de Coletivos Educadores uma das suas estratégias essenciais de implementação”.

Da mesma forma em que os programas de educação relacionados ao meio ambiente evoluíram, o público encontra-se ávido por aprender, especialmente quando a sobrevivência da vida no planeta está na ordem do dia dos noticiários. Este momento em particular é bastante apropriado para se discutir a interação da história da vida na Terra com a do próprio planeta, uma vez que os ouvidos e mentes estão abertos para discutir o papel do homem como agente geológico, construindo e destruindo paisagens e provocando danos profundos ao equilíbrio climático. Ou seja, é um bom momento para a educação científica.

Aos cientistas cabe o papel de promover a divulgação dos conceitos de forma adequada. Aos educadores cabe a transmissão das informações produzidas.

Os museus e centros de ciência vêm cumprindo a função de conectar o cientista diretamente ao público. No entanto, são poucos os cientistas que conseguem a conexão direta, ou seja, falar ao público sem intermediários que decifrem sua linguagem.

No Brasil, informações geológicas colocadas em 17 marcos de concreto implantados ao longo da rodovia SC-438, na denominada Coluna White, na Serra do Rio do Rastro, em Santa Catarina, em 1988, por ocasião do $80^{\circ}$ aniversário da edição do Relatório White de 1908, são um importante exemplo de sinalização geoturística. Também, o Parque do Varvito, em Itu, e o afloramento da rocha moutonée, em Salto, ambos no Estado de São Paulo, são exemplos de sítios onde a geologia é o atrativo. No entanto, projetos de sinalização sistemática dos monumentos geológicos só começaram a despontar no início do século 21.

Em 1993 o DNPM criou o Grupo de Trabalho Nacional de Sítios Geológicos e Paleobiológicos, por solicitação do Comitê Mundial do Patrimônio da UNESCO. Em 1997 foi instituída a Comissão Brasileira dos Sítios Geológicos e Paleobiológicos ou SIGEP que, desde então, vem trabalhando na montagem do banco de dados para indicação dos sítios brasileiros como Patrimônio Natural da Humani- dade à UNESCO. Além de publicação impressa (Schobbenhaus et al., 2002), todas as descrições dos sítios aprovados estão disponíveis em <http://www.unb.br/ig/sigep>.

\section{Algumas ferramentas utilizadas para divulgação e compreensão da Geodiversidade}

\section{Painéis interpretativos e outros materiais}

Os painéis interpretativos são muito usados em UCs (Unidades de Conservação) para descrever aspectos da fauna e flora. Também são comuns na identificação e descrição de monumentos históricos ou arquitetônicos.

A divulgação da geologia por meio de painéis interpretativos colocados em locais de fácil acesso ao público se revelou uma iniciativa de sucesso entre as comunidades locais e se disseminou por vários estados. Entre os geólogos, depois de uma desconfiança inicial, houve uma ampla adesão a projetos desta natureza. Ou seja, uma boa ideia foi lançada no momento oportuno e, assim, pode-se afirmar que houve um avanço nos últimos anos na divulgação da Geologia para a sociedade.

Embora ainda em início de aplicação, já que os trabalhos de sinalização sistemática começaram em 2001 com o Projeto Caminhos Geológicos - PCG do DRM-RJ (Figura 2), lançado em 2000 no $31^{\text {st }}$ International Geological Congress, no Rio de Janeiro, vislumbra-se uma tendência positiva para implementação de iniciativas semelhantes. A Mineropar implantou em 2003 o Projeto Sítios Geológicos e Paleontológicos do Paraná <www.mineropar.pr.gov.br>, com características semelhantes ao PCG. Também em 2003 foi lançado o Projeto Caminhos Geológicos da Bahia que, por ausência de um programa de gestão e de manutenção periódica, perdeu continuidade, apesar de recentes esforços para reativá-lo. Posteriormente, em 2006, no Rio Grande do Norte, o Instituto de Desenvolvimento Econômico e Meio Ambiente do Rio Grande do Norte - IDEMA, inaugurou seu projeto de sinalização, denominado Monumentos Geológicos do Rio Grande do Norte (Cunha, Nesi, Nascimento, 2006). Em Minas Gerais também foi implantado um primeiro painel, em 2007, durante o Simpósio de Geologia do Sudeste, em Diamantina. Em 2009, o Instituto Geológico IG apresentou à comunidade geocientífica o Projeto Monumentos Geológicos de São Paulo.

Em recente pesquisa de opinião realizada no âmbito do Projeto Caminhos Geológicos (Silva, Mansur, Nascimento, 2008), a quase totalidade dos visitantes pesquisados entendeu que a sinalização por painéis é um instrumento eficiente para proteção do patrimônio geológico. Para os que acham que são parcialmente eficientes ou ineficientes, foi perguntado sobre o que poderia ser feito para me- 
lhorar essa eficiência. A maior parte das respostas apontou que "não basta apenas colocar as placas, pois as mesmas por si só não poderiam melhorar a educação da população como um todo". Independente desta opinião, e levando em conta que tanto Gould (1992) quanto Almeida (1931, in Massarani, 1998) têm razão quando apontam para a possibilidade do entendimento dos conceitos pelos leigos, o modelo das placas e a disposição de textos e figuras de painéis implantados estão sendo revistos com ajuda de especialistas em sociolinguística (Jornalismo, Desenho Gráfico e Pedagogia) da Casa da Ciência da UFRJ.

Outros meios também podem ser utilizados como folhetos, CD-ROMs, passeios virtuais, jogos educativos e sítios na Internet. A Mineropar tem lançado folhetos que reproduzem o conteúdo de cada painel implantado e que são distribuídos aos visitantes. A CPRM lançou passeios geoturísticos virtuais a locais de grande interesse geológico, como Coluna White, Aparados da Serra e Quadrilátero Ferrífero, tanto em CD-ROM quanto em seu sítio na Internet <www.cprm.gov.br>. Tem produzido, também, mapas geoturísticos, como o da Chapada Diamantina, também disponível na Internet.

Em <www.caminhosgeologicos.rj.gov.br> (Garcia et. al., 2008) é possível conhecer todos os painéis implantados pelo PCG, navegar em um mapa eletrônico, aprender com jogos educativos (labirinto, palavras cruzadas, caçapalavras e quebra-cabeças), mandar postais e acessar todos os trabalhos científicos já produzidos no âmbito do projeto. Porém, a apresentação do inventário do patrimônio geológico fluminense on-line é um dos seus itens mais importantes. Ainda está em fase de implantação e testes, mas busca atender aos itens básicos de inventário, valoração quantitativa, valorização e divulgação de que fala Brilha (2005), quando apresenta as etapas básicas para uma estratégia de Geoconservação.

\section{Projetos de educação em Geologia para as escolas}

Os professores do ciclo fundamental e médio muitas vezes não possuem conhecimento suficiente para orientar e esclarecer seus alunos sobre os conceitos geológicos. Isto faz com que o módulo de ensino da Geologia seja muito mais curto do que aqueles relacionados à Biologia e à Geografia física e humana, que são as bases da formação dos professores, em geral biólogos ou geógrafos. Isto só agrava a situação, porque já é pequeno o espaço destinado para a Geologia na grade curricular dos ensinos fundamental e médio. Quanto à discussão da relação da geodiversidade com a biodiversidade, menor (ou nenhum) é o destaque dado ao meio físico, o que afasta mais ainda os dois conceitos e dilui o interesse que poderia ser desperta- do para uma visão integrada do planeta. Também, no âmbito da educação formal, deve-se destacar a baixa qualidade dos livros didáticos, em especial nas seções dedicadas à Geologia, onde, por vezes, graves erros convivem com informação incompleta e de pouco interesse prático.

Na direção da solução deste problema, a UNICAMP lançou em 1998 o Curso de Ciências da Terra, inovando nos bacharelados em Geologia e Geografia, cuja opção por cada uma das áreas é feita pelos alunos após cursarem em conjunto os dois primeiros semestres. Carneiro et al. (2008) avaliam positivamente a aprendizagem e a experiência docente nas disciplinas relacionadas aos trabalhos de campo com os alunos do curso.

A USP lançou em 2003 o curso de licenciatura em Geociências e Educação Ambiental, "voltado à compreensão integrada da história e dinâmica do planeta, base para a formação de cidadãos conscientes e comprometidos com o desenvolvimento sustentável da Sociedade" $<$ http://www.igc.usp.br>. Um dos seus objetivos é a formação de educadores para atuação no ensino escolar ou informal. O curso foi reformulado em 2008.

Em 2008 a UFRJ realizou seu primeiro vestibular para o curso de bacharel em Ciências Matemáticas e da Terra, agrupando os Institutos de Física, Geociências e Matemática e o Observatório do Valongo, num curso que tem entre seus objetivos formar profissionais capazes de agregarem-se aos cursos de formação para pesquisadores, professores e demais profissionais nas áreas de Ciências da Natureza e Matemática <http://omnis.if.ufrj.br/ marta/cmt/informacoes.html>.

Nas ações relacionadas ao apoio ao desenvolvimento do ensino formal, devem ser citados os casos do Projeto Caminhos Geológicos do Estado do Rio de Janeiro e do Projeto Sítios Geológicos e Paleontológicos do Paraná, ambos coordenados pelos Serviços Geológicos Estaduais. Nestes projetos existe a preocupação de relacionar a implantação de painéis interpretativos com um projeto de educação em Geologia para as escolas. Textos e coleções de rochas e minerais são doados às escolas e organizadas palestras para alunos e treinamento para professores nos temas geológicos. Portanto, a divulgação da Geologia para toda a sociedade é reforçada estrategicamente no meio escolar.

Um exemplo de interferência no sistema formal de ensino foi o realizado durante a execução do projeto "Planejamento Conservacionista das Terras e Modelagem Preditiva de Sistemas Aquíferos do Cristalino para a Recarga Hídrica em Bacias Hidrográficas de Relevo Acidentado”, financiado pelo Banco Mundial/PRODETAB (Freitas et al., 2005). Entre as várias ações do projeto, entre 2003 e 2007, especial destaque deve ser dado àquelas relacionadas à promoção da percepção ambiental (Capeche et al., 2006) com professores e alunos em todas as escolas do município. Com a intenção de proporcionar uma tomada de consciência so- 
bre o ambiente, foram realizados treinamento com todos os professores da rede municipal e oficinas e palestras com os alunos. O aprendizado dos conceitos foi reforçado pela produção de dois cadernos interativos Se esse rio fosse meu... (Talarico, 2004) e Minha terra, meu futuro (Talarico et al., 2005), para a segunda e quarta série, respectivamente. Os professores aplicaram os cadernos durante o ano letivo nas 12 escolas do município. Em 2004, ao fim do primeiro ano de aplicação do caderno Se esse rio fosse meu foi realizado um concurso de desenhos e redações (Freitas, 2004) entre os alunos de todas as escolas. Cerca de 200 desenhos foram produzidos. Da análise desses desenhos e das redações foi possível identificar o alto grau de absorção dos conceitos ambientais repassados em sala de aula. O DRM-RJ assumiu a responsabilidade de transformá-los em painéis do Projeto Caminhos Geológicos (Mansur et al., 2005 e Mansur e Nascimento, 2007).

Importante iniciativa de divulgação científica nas escolas é o programa Iniciação Científica Jr, apoiado pelo CNPq/MCT <http://www.cnpq.br/normas/rn_06_017_anexo5.htm> em todos os estados da federação e no Distrito Federal, pela inserção do pesquisador no cotidiano dos alunos e professores. Estes programas distribuem bolsas para alunos do ensino médio da rede pública que participam de pesquisa científica orientada. No caso do Rio de Janeiro, o programa Jovens Talentos para a Ciência é uma iniciativa da Fundação Carlos Chagas de Apoio à Pesquisa do Estado do Rio de Janeiro (FAPERJ), do Centro de Ciências do Estado do Rio de Janeiro (CECIERJ) e da Fundação Oswaldo Cruz (FIOCRUZ). Existe desde 1999 e tem entre seus objetivos contribuir para a difusão de conhecimentos científicos pela articulação entre ensino e pesquisa e pela desmistificação da ciência <http://www.faperj.br/interna.phtml?obj_ id=79>. Apesar do sucesso do programa que existe há 10 anos no estado e que já apoiou 4.284 alunos em 38 municípios (Jorge Belizário, 2009, por correio eletrônico), ainda são poucos os projetos na área de Geologia. Nos municípios de Itaboraí, Saquarema e Santo Antônio de Pádua projetos específicos de Geologia e Paleontologia foram ou estão sendo desenvolvidos.

\section{Museus e Centros de Ciências}

Os museus e centros de ciências cumprem importante papel na divulgação científica. A publicação Centros e Museus de Ciência do Brasil (Brito, Ferreira, Massarani, 2005), disponível em <http://www.abcmc.org.br/publique1/media/ centrosciencia.pdf $>$, dá uma mostra da ampla gama de possibilidades de visitação a locais onde a ciência é o tema da mostra. Das 112 instituições listadas na publicação, 14 têm relação com a Geologia, em geral pela existência de coleção de rochas, meteoritos, minerais e fósseis.
As exposições são cada vez mais interativas e as instituições buscam ouvir a opinião dos usuários para saber o grau de entendimento e satisfação com a visitação, inclusive com metodologia específica para aferir o aprendizado das crianças. Com esta preocupação, em dezembro de 2008, foi inaugurado o Museu da Geodiversidade da UFRJ (Figura 3), que foi concebido para mostrar que rochas, minerais, fósseis, solos e paisagem são substrato da vida e que o homem pode atuar como agente geológico. Esta abordagem inovadora confere um caráter diferenciado à exposição.

A experiência com atividades desenvolvidas no interior fluminense tem mostrado que há um interesse bastante forte dos municípios para montagem de museus em seus territórios. Muitos já construíram mostras permanentes com peças, fotografias, mapas e objetos de sua história, criando suas casas de cultura, onde também expõem sua pré-história contada por sambaquis, cerâmicas e artefatos (Figura 4). A ciência também vem despertando recente interesse e espera-se que esta tendência se firme.

\section{Participação em eventos de caráter científico abertos à comunidade}

A realização anual da Semana Nacional de Ciência e Tecnologia tem sido um importante indutor de conhecimento sobre os processos físicos, químicos, biológicos e geológicos para o público visitante, em particular para os estudantes, principais usuários dos "serviços” científicos e tecnológicos oferecidos. Este é um excelente fórum para divulgação das ciências da Terra e acredita-se que pode ser mais bem aproveitado para apresentar a Geologia de forma atrativa e simples. Uma experiência que produz resultados de grande qualidade é a organização de excursões de campo (abertas à participação da comunidade) até sítios de interesse geológico.

Filmes comerciais para o público jovem, seguidos de debates com temas geológicos, foram muito apreciados durante a Semana de C\&T em Santo Antônio de Pádua RJ, em 2007 e 2008, organizada pela UFF - Universidade Federal Fluminense, onde mudanças climáticas, evolução da vida na Terra, contaminação de águas subterrâneas foram discutidos após apresentação de filmes como A Era do Gelo I e II e Erin Bronkovitz, por exemplo.

As reuniões anuais da SBPC que contam, inclusive, com um espaço e programação específica para o público jovem, a SBPC-Jovem, também são pouco utilizadas pela comunidade geológica. Em 2007, no encontro ocorrido em Belém - PA, a SBGf - Sociedade Brasileira de Geofísica organizou um espaço com cartazes, explicações e demonstrações sobre métodos geofísicos que gerou grande inte- 
resse no público presente. Em 2008, em Campinas, a participação das Geociências foi muito pequena nas palestras, oficinas e exposição.

As prefeituras municipais também podem criar seus próprios fóruns de comunicação com a sociedade e, com base numa proposta de educação ambiental, realizar atividades comunitárias que promovam a inclusão da população no meio científico. Em Cabo Frio, a prefeitura vem apoiando diversas pesquisas geológicas, cujos resultados foram apresentados no I, II e III Simpósio Municipal de Geologia de Cabo Frio - RJ, em 2005, 2007 e 2008, respectivamente, para estudantes, professores, pescadores, proprietários de pousadas e empresas de turismo, ONGs e população em geral, como forma de prestação de contas (Figura 5).

\section{Projetos específicos de divulgação científica}

Alguns temas podem ser de especial interesse do público. Um exemplo é a divulgação da passagem de Charles Darwin pelo Brasil, e pelo Estado do Rio de Janeiro em particular. Este fato levou à concepção e execução do Projeto Caminhos de Darwin, sob coordenação geral do MCT - Ministério da Ciência e Tecnologia e coordenação executiva da Casa da Ciência da UFRJ e do DRM-RJ/Projeto Caminhos Geológicos, em comemoração ao bicentenário do nascimento de Darwin e 150 anos do lançamento da Teoria da Evolução das Espécies pela Seleção Natural, cujo livro foi editado em 1859. A teoria foi comunicada ao público, em conjunto com Alfred Wallace, em 1858. Os doze municípios fluminenses visitados e citados por Darwin em seu diário receberam sinalização por meio de marcos comemorativos e placas de estrada (Figura 6). Um amplo esforço de divulgação junto às Secretarias de Educação proporcionou a geração de trabalhos científicos, artísticos e históricos sobre a passagem do naturalista britânico, feitos por alunos, professores e pesquisadores destes municípios. A geologia foi contemplada pela localização dos afloramentos descritos por Darwin e pela montagem de uma coleção de rochas e minerais existentes ao longo do trajeto por ele percorrido. Estes afloramentos estão sendo estudados para serem sinalizados e protegidos como Patrimônio Geológico do tipo História da Ciência. O projeto começou em 2008 e teve seguimento em 2009 e gerou grande interesse na mídia e matérias em jornais, revistas e TVs que noticiaram as informações levantadas e as atividades desenvolvidas, entre elas uma expedição que durou 4 dias e contou com a presença de cientistas, jornalistas, professores, estudantes, artistas e também de Randal Keynes, tataraneto de Darwin <www.casadaciencia.ufrj.br/caminhosdedarwin>.

\section{GEOPARQUES}

Em 2001, o Comitê executivo da UNESCO sugeriu aos países membros que estabelecessem parques naturais com características geológicas especiais e produziu uma resolução para promover a construção de uma rede global de sítios de especial valor como patrimônio geológico. Em fevereiro de 2002, o Comitê Executivo do IGCP - Executive International Geological Correlation Program, sugeriu à Divisão de Ciências da Terra da UNESCO que estabelecesse uma rede de Geoparques com 3 objetivos: 1. cuidar da saúde ambiental; 2. promover a educação geocientífica; 3. criar uma atmosfera saudável local para o desenvolvimento econômico sustentável <http://www.globalgeopark. org/publish/portal1/tab115/>.

Um geoparque é uma área com significativo patrimônio geológico e com uma estrutura de gestão coerente e forte, baseada em uma estratégia de desenvolvimento econômico sustentável. Um Geoparque cria oportunidades de emprego para as pessoas que vivem no local, para quem traz benefícios econômicos reais, em geral por meio do turismo. Nele, o conhecimento geológico deve ser compartilhado com o grande público e deve ser estabelecida uma conexão com os aspectos do ambiente natural e cultural que, em geral, estão relacionados ou são determinados pela geologia <http://www.globalgeopark.org/publish/ portal1/tab190/>.

Existem hoje 58 geoparques em 18 países que formam uma Rede Global (números de junho de 2009) onde o Brasil está representado pelo Geoparque Araripe <http://portal.unesco.org/science/en/ev.php-URL_ID=7405\&URL_ DO=DO_TOPIC\&URL_SECTION=201.html $>$.

O documento "Guidelines and Criteria for National Geoparks seeking UNESCO's assistance to join the Global Geoparks Network (June 2008)" disponível em $<$ http://www.unesco.org/science/earth/doc/geopark/200 8guidelinesJuneendorsed.pdf $>$, trata dos critérios gerais para a declaração de Geoparques chancelados pela UNESCO. Estas áreas devem cumprir com os seguintes requisitos básicos:

a. Tamanho e características: área bem delimitada, com tamanho que permita o desenvolvimento local de atividades econômicas e culturais, como o geoturismo, por exemplo. Os sítios geológicos devem ter especial importância, raridade ou beleza e devem representar a evolução geológica da região.

b. Gestão e envolvimento local: deve possuir um plano de gestão, com adequada infraestrutura, suporte financeiro e mão de obra qualificada. Deve ser construído de baixo para cima. Não basta ter excelentes geossítios na área, mas é fundamental que a proposta de criação do geoparque seja 


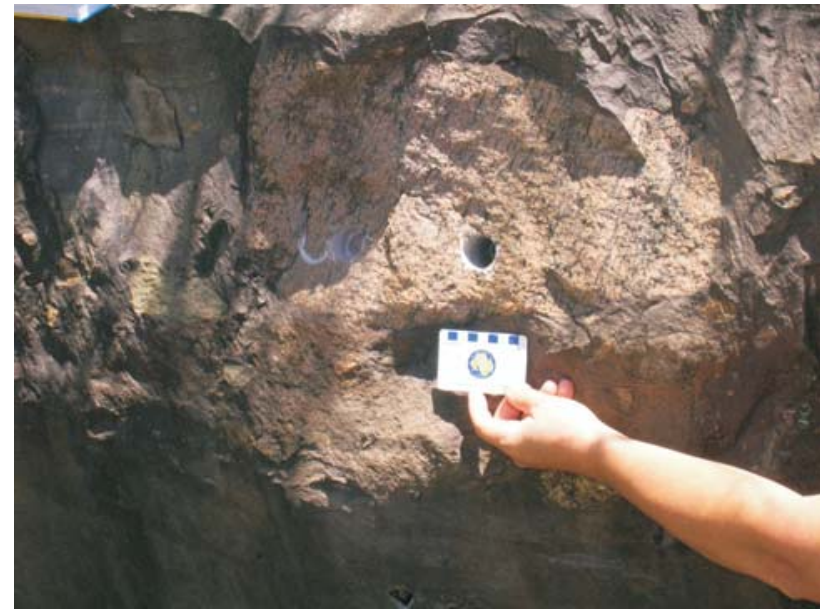

Figura 1. Fotografia de um afloramento de diamictito da Formação Bebedouro, na Chapada Diamantina (corte de estrada na Rodovia BR-242). A extração de amostras do clasto de gnaisse causou danos ao afloramento que perdeu qualidade para a retirada de fotografias. Este é um ponto de parada obrigatória de excursões didáticas e científicas na região. Nestes casos, a amostra poderia ter sido coletada em outra porção do afloramento, preservando sua integridade como ponto de referência geológica (Foto: DRM-RJ).

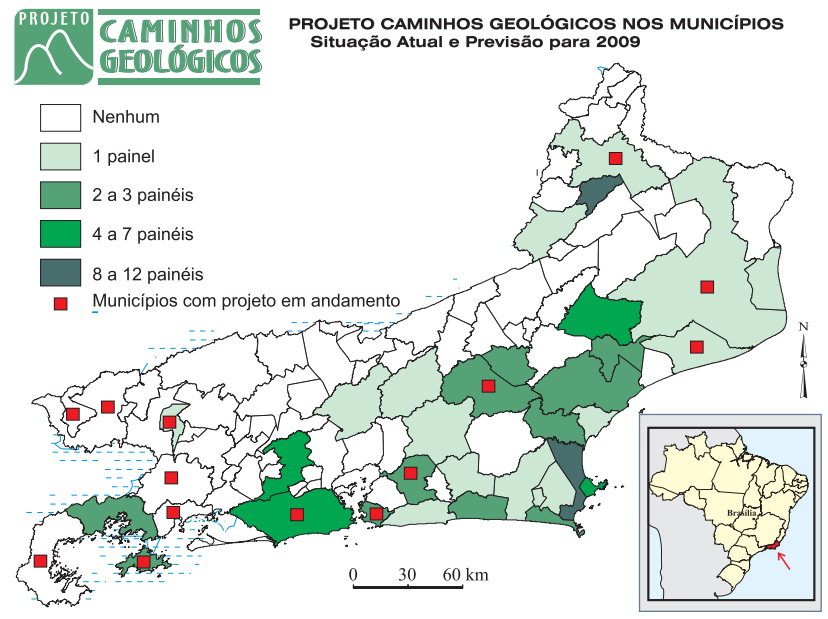

Figura 2. Mapa do Estado do Rio de Janeiro com a distribuição dos painéis do PCG em relação aos municípios. Até junho de 2009, foram implantados 84 painéis em 30 dos 92 municípios fluminenses.

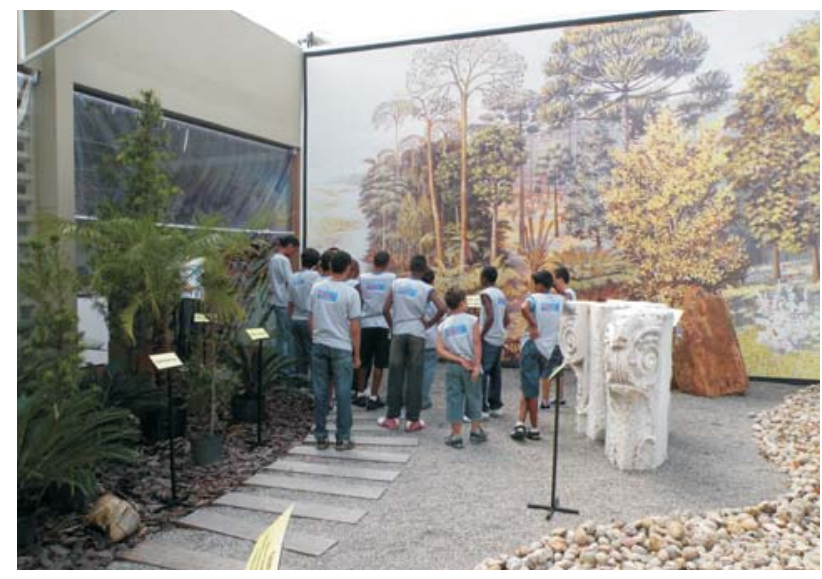

Figura 3. Alunos visitam o Museu da Geodiversidade da UFRJ (Foto: UFRJ).

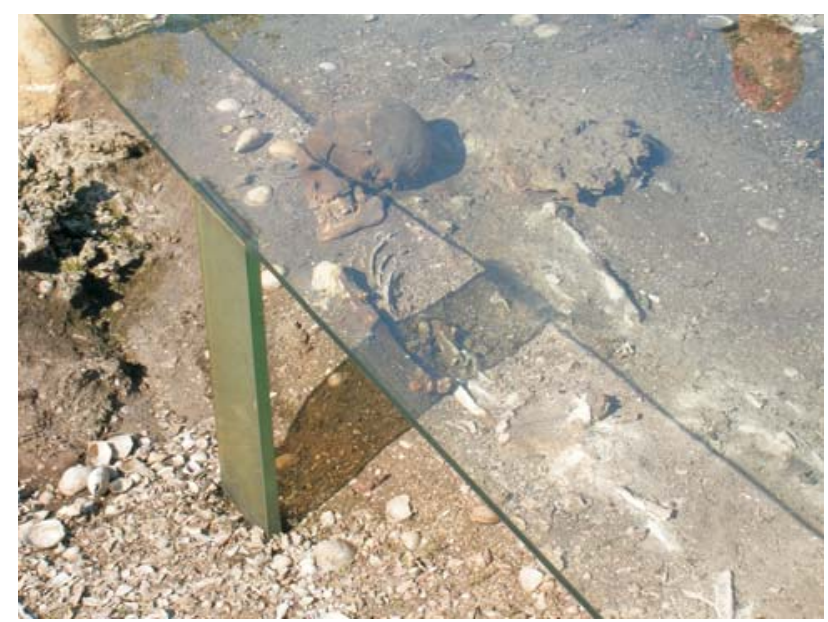

Figura 4. Sambaqui da Beirada, em Saquarema. Exposição in situ do patrimônio arqueológico (Foto: DRM-RJ).

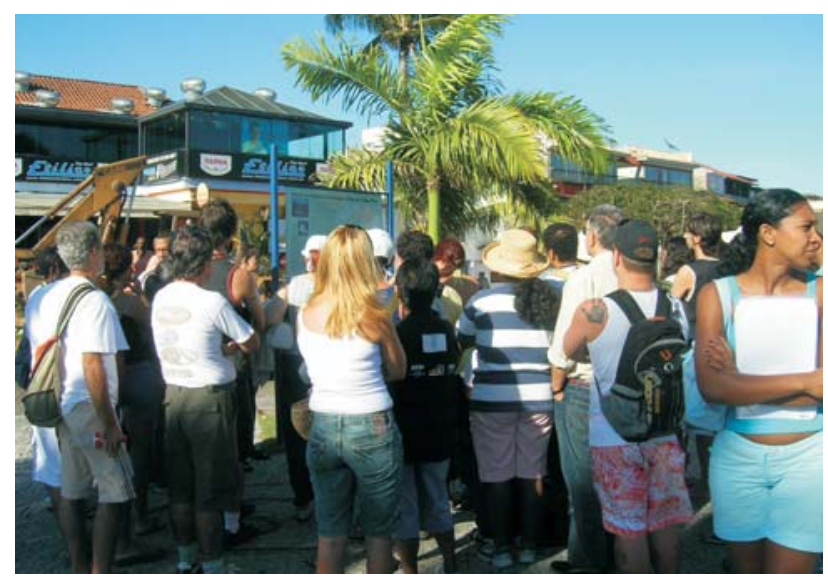

Figura 5. Excursão de campo ocorrida durante o ll Simpósio Municipal de Geologia de Cabo Frio. O Painel do PCG foi utilizado como material didático de apoio (foto: DRM-RJ). 

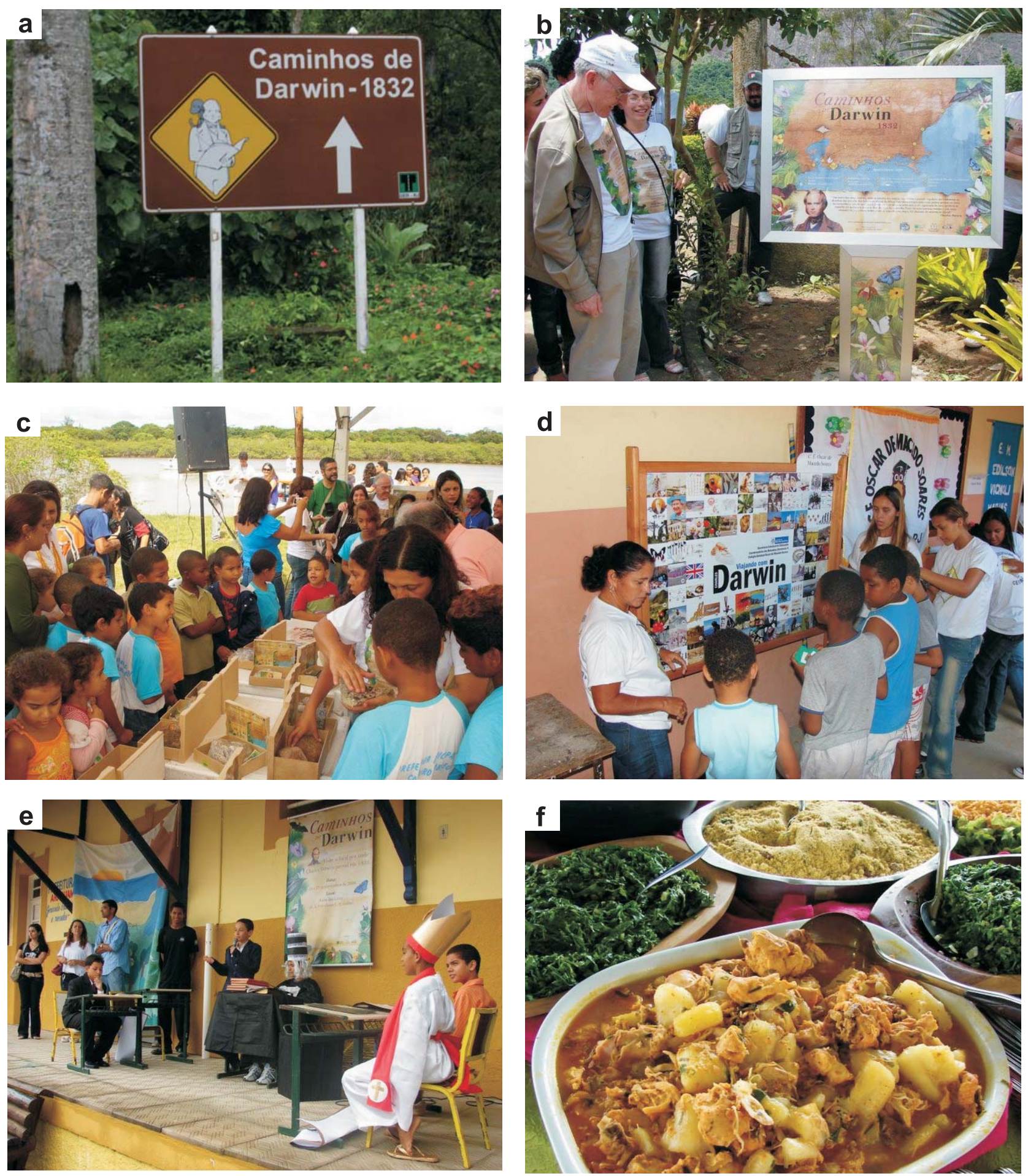

Figura 6. a. Placa de sinalização do local onde o marco comemorativo foi implantado (Solar da Imperatriz - Jardim Botânico - Rio de Janeiro) (Foto: DRM-RJ). b. Marco comemorativo da passagem de Charles Darwin em Maricá (Fazenda Itaocaia) e Randal Keynes, tataraneto de Darwin (Foto: Casa da Ciência). c. Coleção de amostras de rochas e minerais coletadas ao longo do trajeto percorrido por Darwin (Barra de São João, Casimiro de Abreu) (Foto: DRM-RJ). d. Pesquisa desenvolvida pelos alunos em Saquarema (Foto: Casa da Ciência). e. Teatro sobre o conflito entre darwinismo e religião, organizado por professores e alunos de Araruama (Foto: Casa da Ciência). f. Gastronomia - o que Darwin comeu em seu jantar em abril de 1832 em Cabo Frio (Foto: Casa da Ciência). 
apoiada pela população e pelo gestor local. No seu planejamento devem estar envolvidas as autoridades públicas, comunidades locais, interesses privados e programas de ensino e pesquisa. A proposta de turismo sustentável ou outra atividade econômica qualquer deve estar ligada à comunidade local.

c. Desenvolvimento Econômico: Para a Comissão Mundial sobre o meio Ambiente e Desenvolvimento em Our Common Future (1987), sustentável é o desenvolvimento que dá conta das necessidades da presente geração sem comprometer a capacidade das futuras gerações em garantir suas próprias necessidades. Assim, um dos objetivos estratégicos de um geoparque é estimular a atividade econômica e o desenvolvimento sustentável por meio de apoio às atividades sócio-econômicas e culturais da população. Deve-se buscar o estímulo à criação de empreendimentos locais, pequenos negócios, artesanato, iniciativas de treinamento de pessoal que gerem novos empregos e recursos (ex: geoturismo e geoprodutos).

d. Educação: além de prover e organizar infraestrutura, ferramentas e atividades para divulgação geocientífica e ambiental para o público e manter relacionamento com pesquisadores e cooperação com universidades, o geoparque deve estimular a interação entre os geocientistas e a população local. O sucesso das atividades educacionais depende não somente dos programas de geoturismo, comunicação e logística oferecidos ao visitante, mas também deve considerar o contato com a população, a mídia e os tomadores de decisão locais. Devem ser previstas ações de transferência de conhecimento ao morador local (como, por exemplo, treinamento de guias de visitantes), uma vez que a aceitação da filosofia dos geoparques pela comunidade é de primordial importância para o sucesso da implantação e manutenção dos mesmos. Os instrumentos a serem utilizados são variados, como museus, centros interpretativos e educacionais, trilhas, roteiros guiados, mapas e literatura em linguagem adequada e mídias eletrônicas. A transferência de informação também pode se dar por recepção de escolas (alunos e professores), seminários, textos científicos para interessados e projetos com moradores que desejam aprender para melhorar seu contato com os visitantes. Do ponto de vista da educação formal, é apreciada a criação de currículos específicos para as escolas locais, onde os conceitos sobre Geologia, Geomorfologia, Geografia Física e Patrimônio Geológico ajudem na preservação do geoparque e ampliem o sentimento de pertencimento e autoestima da população. Todas as atividades educacionais devem refletir considerações éticas em torno da proteção ambiental de forma holística.

e. Proteção e Conservação: um geoparque não é uma nova categoria de Unidade de Conservação, mas deve promover a proteção do patrimônio geológico, de acordo com a legislação vigente, de âmbito municipal, estadual ou nacio- nal. De modo a que seja imparcial na gestão, o administrador do geoparque não deve participar diretamente da arrecadação de recursos pela venda de produtos no seu interior.

Chris Woodley-Stewart, gestor do Geoparque de North Pennines, Reino Unido, fez um depoimento sobre a essência dos geoparques que reflete bem a necessidade da inserção da população na gestão do espaço delimitado: “Geoparks are not just about rocks - they are about people. It is crucial that they get involved-we want to see as many people as possible getting out and enjoying the geology of the area. Our aim is to maximise geotourism (...) for the benefit of the local economy and to help people to understand the evolution of their local landscape." <http://portal.unesco. org/science/en/ev.php-URL_ID=6400\&URL_DO=DO_ TOPIC\&URL_SECTION=201.html>.

\section{CONSIDERAÇÕES FINAIS}

A Geoconservação ou Conservação do Patrimônio Geológico depende do apoio da sociedade para se concretizar. Porém, este apoio só será obtido se houver um entendimento da importância destes locais de interesse geológico, o que pressupõe a absorção de algumas informações e conceitos básicos pelos cidadãos. As iniciativas em curso no Brasil mostram que é possível promover projetos de sucesso na popularização das Geociências para as comunidades. Porém, as experiências apontam para o fato de que é fundamental a existência de um programa de divulgação científica articulado, que contemple o sistema educacional formal e a população como um todo. Os museus e centros de ciências e as ações de universidades vêm complementando esta lacuna, porém, os resultados são ainda modestos, dadas as dimensões do Brasil e as necessidades de investimentos.

Numa estratégia de conservação do patrimônio geológico, o levantamento dos locais de interesse, sua divulgação e proteção, são essenciais. A divulgação é um dos pontos mais críticos, porque pressupõe o repasse da informação pelo pesquisador, a tradução dos conceitos envolvidos para uma linguagem adequada e o entendimento do público-alvo. O ensino formal parece ser um dos melhores locais para exercitar as ferramentas existentes para popularização da ciência, porque alunos e professores estão abertos à aprendizagem. Assim, para que se atinja o objetivo de informar, numa linguagem apropriada e sem perder a profundidade do conteúdo científico, é essencial e urgente uma aproximação entre as universidades, entidades técnico-científicas e serviços geológicos (do Brasil e dos estados) com as escolas para informar melhor aos estudantes e propiciar um aprimoramento para os professores. Neste último aspecto, observam-se iniciativas de algumas univer- 
sidades para formação de profissionais e professores com melhor conhecimento dos conceitos geológicos.

Deve-se deixar bem claro que promover a educação formal não é função de museus, centros de ciência e nem organizações que se dedicam à divulgação científica. Estes são apenas ferramentas para fazer chegar o conhecimento em ciência e tecnologia para todos os cidadãos. No entanto, face aos problemas existentes para viabilizar um ensino de qualidade na área de ciências no Brasil, muitas dessas instituições buscam uma interface com as escolas na tentativa de acrescentar um componente atrativo para o aluno e um suporte a mais para o professor.

Enquanto isto, é necessário que haja um aprofundamento da discussão já existente junto aos Ministérios da Educação e da Ciência e Tecnologia para a importância de se prover maior espaço para os conceitos geológicos na grade curricular oficial. Esta é uma área em que as entidades técnico-científicas devem interferir, no sentido de municiar as autoridades educacionais de informações sobre a necessidade de melhorias urgentes, inclusive na qualidade do material didático colocado à disposição dos alunos.

Ressalta-se, ainda, que atualmente poucos estados brasileiros possuem uma entidade específica para gestão dos recursos geológicos, bem como são raríssimos os municípios em tais condições. Isto coloca nas mãos das universidades, entidades técnico-científicas, órgãos de meio ambiente e, por vezes, do Serviço Geológico do Brasil, a tarefa de agir para eleger, divulgar e proteger o patrimônio geológico de âmbito estadual. Este é um aspecto que também deve ser avaliado cuidadosamente, porque a proteção e a conservação do patrimônio geológico requerem gestão científica e administrativa, além de fiscalização periódica (monitoramento). Em geral, o papel de denunciar a degradação dos geossítios tem sido cumprido por ONGs ambientalistas, assessoradas por pesquisador(es) das áreas afetadas.

Por outro lado, parece que muitos geólogos e instituições ainda não se dispõem a participar de eventos, projetos e ações de popularização da Geologia, dada a pequena parcela de atividades nesta área da ciência, se comparadas às demais, nos fóruns abertos à participação popular no Brasil.

E, finalmente, entende-se que a figura do geoparque pode ser extremamente importante para a divulgação do patrimônio geológico e sua conservação. Porém, seu ponto mais delicado é a inserção das comunidades do entorno na sua gestão, de forma a que lhe dê sustentabilidade social e financeira. Sem isto e, portanto, sem um programa de divulgação científica, este fator básico não será alcançado. O desafio a ser vencido é o de romper com o isolamento imposto por uma linguagem entendida por poucos.

\section{REFERÊNCIAS}

BOULTON, G. S. The earth system and the challenge of global change. In: GORDON J. E.; LEYS, K. F. Earth science and the natural heritage: interactions and integrated manangement. Edinburgh: Scottish Natural Heritage, 2001. p. 26-54.

BRILHA, J. Património geológico e geoconservação: a conservação da natureza na sua vertente geológica. Braga: Palimage Editores. 2005. 190 p.

BRITO, F.; FERREIRA, J. R.; MASSARANI, L. (Eds.). Centros e museus de ciências do Brasil. Rio de Janeiro: ABCMC/ UFRJ/Casa da Ciência/ FIOCRUZ/ Museu da Vida, 2005. 140 p. Disponível em <www.abcmc.org.br/publique1/media/ centrosciencia.pdf>. Acesso em 20 abr. 2009.

CANDOTTI, E. Ciência na educação popular. In: MASSARANI, L.; MOREIRA, I. C.; BRITO, F. Ciência e Público: caminhos da divulgação científica no Brasil. Rio de Janeiro: Casa da Ciência, UFRJ, 2002. p. 15 - 23. (Série Terra Incógnita, 1).

CAPECHE, C. L.; PRADO, R. B.; MANSUR, K. L.; PIMENTA, T. S.; FREITAS, P. L.; TALARICO, T. E.; FIDALGO, E. C. C.; MACEDO, J. R.; BHERING, S. B. Atividades de percepção ambiental desenvolvidas pelo Projeto Aquíferos em São José de Ubá - Rio de Janeiro. In: WORKSHOP DE INTEGRAÇÃO DE INFORMAÇÕES OBTIDAS NO ÂMBITO DO PROJETO PRODETAB AQÜÍFEROS, 2006, Rio de Janeiro. Anais... Rio de Janeiro: Embrapa Solos, 2006. 1 CD-ROM.

CARNEIRO, C. D. R.; GONÇALVES, P. W.; CUNHA, C. A. L. S.; NEGRÃO, O. B. M. Docência e trabalhos de campo nas disciplinas Ciência do Sistema Terra I e II da UNICAMP. Revista Brasileira de Geociências, n. 38, v.1, p. $130-142$.

CUNHA, E. M. S.; NESI, J. R.; NASCIMENTO, M. A. L. Projeto Monumentos Geológicos do Rio Grande do Norte: a divulgação e conservação do patrimônio geológico potiguar. In: CONGRESSO BRASILEIRO DE GEOLOGIA, 43., 2006, Aracaju. Anais... Aracaju: Sociedade Brasileira de Geologia. 2006. p. 90.

FREITAS, P. L. Curso de Educação Ambiental para Professores do Ensino Fundamental. Embrapa Solos, 2004. 31 p. (Relatório Final).

FREITAS, P. L.; FIDALGO, E. C. C.; MANSUR, K. L.; BENITES, V. M.; FERNANDES, N. F. Uma proposta de 
planejamento conservacionista das terras e modelagem preditiva de sistemas aqüíferos do cristalino. In: SIMPÓSIO DE GEOLOGIA DO SUDESTE, 9., 2005, Niterói, Anais... Niterói: Sociedade Brasileira de Geologia, 2005, p. 112.

GARCIA, R. A. N.; FARIA, T. T.; FALHEIRO, P.; FREITAS, A. C. A.; MANSUR, K. L.; NASCIMENTO, V.; SOARES, A. Projeto Caminhos Geológicos na Internet: software livre e interatividade para gestão do patrimônio geológico fluminense. In: 44 Congresso Brasileiro de Geologia, 44., 2008, Curitiba. Anais... Curitiba: Sociedade Brasileira de Geologia, 2008. p. 406.

GORDON, J. E.; LEYS, K. F. Earth science and the natural heritage: developing a more holistic approach. In: GORDON, J. E.; LEYS, K. F. Earth Science and the Natural Heritage: Interactions and Integrated Manangement. Edinburgh: Scottish Natural Heritage, 2001. p. 5-18.

GOULD, S. J. Viva o Brontossauro: reflexões sobre história natural. São Paulo: Companhia das Letras, 1992. 523 p.

LIMA, F. F. Proposta metodológica para a inventariação do patrimônio geológico brasileiro. 2008. 100 p. Dissertação (Mestrado). Universidade do Minho, Braga.

MANSUR, K. L.; FREITAS, P. L.; TALARICO, T. E.; CAPECHE, C. L.; GUEDES, E.; GUIMARÃES, P. V.; MEDEIROS, F. Projeto Caminhos Geológicos nas escolas: o caso de São José de Ubá - RJ. In: SIMPÓSIO DE GEOLOGIA DO SUDESTE, 9., Niterói, 2005. Anais... Niterói: Sociedade Brasileira de Geologia, 2005, p. 207.

MANSUR, K. L.; NASCIMENTO, V. M. R. Disseminação do conhecimento geológico: metodologia aplicada ao Projeto Caminhos Geológicos. In: SIMPÓSIO DE PESQUISA EM ENSINO E HISTÓRIA DE CIÊNCIAS DA TERRA, 1/SIMPÓSIO NACIONAL SOBRE ENSINO DE GEOLOGIA NO BRASIL, 3., 2007, Campinas. Anais eletrônicos... Campinas: UNICAMP, 2007. 1 CD-ROM. Disponível em: <www.ige.unicamp.br/simposioensino/artigos/025.pdf>. Acesso em: 10 jun. 2008.

MASSARANI, L. A divulgação científica no Rio de Janeiro: algumas reflexões sobre a década de 20. 1998. 177 p. Dissertação (Mestrado) - Universidade Federal do Rio de Janeiro, UFRJ-IBICT, Rio de Janeiro.

MASSARANI, L.; MOREIRA, I. C.; BRITO, F. Ciência e Público: caminhos da divulgação científica no Brasil. Rio de Janeiro: Casa da Ciência, UFRJ, 2002. 232 p. (Série Terra Incógnita, 1).

MMA - MINISTÉRIO DO MEIO AMBIENTE. Departamento de Educação Ambiental. Disponível em: $<$ www.mma.gov.br/sitio/index.php?ido=conteudo.mo nta\&idEstrutura $=20 \& i d C o n t e u d o=4028>$. Acesso em: 17 fev. 2009.

MONDÉJAR, F. G. El Patrimonio Geológico: cultura social y ordenación del territorio. In: CONGRESO INTERNACIONAL SOBRE GEOLOGIA Y MINERIA EM LA ORDENACIÓN DEL TERRITORIO Y EN EL DESARROLLO, 1., 2007, Utrillas. Librillo Preliminar de Actas. Utrillas: SEDPGYM, 2007. p. 6-7.

SCHOBBENHAUS, C.; CAMPOS, D. A.; QUEIROZ, E. T.; WINGE, M.; BERBERT-BORN, M. L. C. (Eds.). Sítios Geológicos e Paleontológicos do Brasil. Brasília: DNPM/CPRM, 2002. 554 p.

SILVA, A. S.; MANSUR, K. L.; NASCIMENTO, V. Aperfeiçoando o Projeto Caminhos Geológicos: uma experiência de Sucesso na Popularização da Geologia do Estado do Rio de Janeiro. Rio de Janeiro: FAPERJ. 2008. (Relatório Final do Projeto FAPERJ).

TALARICO, T. E. Se esse Rio fosse meu.... Caderno Interativo de Educação Ambiental (Ensino Fundamental - Ciclos I e II). Rio de Janeiro: Embrapa Solos, 2004. 54 p.

TALARICO, T. E.; FREITAS, P. L.; CAPECHE, C. L.; MANZATTO, C. V.; FIDALGO, E. C. C.; SILVA JUNIOR, G. C. DA; MENEZES, J.; MANSUR, K. L.; SILVA, L. P. DA; PRADO, R. B.; FERRAZ, R. P. D. Minha terra, meu futuro: educação ambiental. Rio de Janeiro: Embrapa Solos, 2005. 104 p.

UCEDA, A. C. El Patrimonio Geologico: ideas para su protección, conservación y utilización. In: MOPTMA MIN. OBR. PÚBL. TRANP. MED. AMB. El patrimonio geológico. Bases para su valoración, protección, conservación y utilización. Madrid. 1996. p. 17-27. 